\title{
Pesquisas de opinião e preferência sobre tipografia para crianças
}

\author{
Opinion and preference research on typography for children
}

\author{
Letícia Rumjanek, Washington Dias Lessa
}

tipografia, tipografia para crianças, legibilidade

\begin{abstract}
Considerando pesquisas de legibilidade com crianças leitoras iniciantes, além da avaliação de parâmetros objetivos relacionados ao desempenho de leitura, alguns autores procuram ouvir a opinião e a preferência dos participantes quanto às opções tipográficas utilizadas na pesquisa. Esta iniciativa, que pode ser realizada tanto com as próprias crianças quanto com professores alfabetizadores, busca, muitas vezes, gerar dados que subsidiem a seleção de parâmetros a serem considerados em um teste de desempenho de leitura. A investigação de fatores subjetivos, como a opinião de leitores, pode levantar novas questões a serem abordadas em pesquisas sobre o tema, assim como a uma compreensão mais abrangente da prática da leitura.
\end{abstract}

typography, typography for children, legibility

In regard to legibility research with children starting to learn to read, besides the evaluation of objective parameters related to reading, some authors try to listen to the participants' opinion and preference concerning the typographic options used in the research. This approach can be carried out both with children and teachers, and it strives for obtaining data that may help in selecting the parameters to be considered in a reading performance test. The investigation of subjective factors, such as the opinion of readers, may bring about new issues to be considered in new studies of the theme, and also a broader comprehension of reading practice.

\section{Introdução}

Tradicionalmente, o objetivo principal das pesquisas de legibilidade é encontrar condições ótimas de leitura. Deste modo, seus autores buscam entender quais composições tipográficas e desenhos de letras acarretam o aumento do desempenho de leitura, tendo em vista a otimização do processo de aquisição da informação pelo usuário (SBDI, 2006).

O desempenho de leitura é comumente avaliado em experimentos práticos por meio de critérios quantificáveis que visam a medir, de um modo geral, a precisão de reconhecimento de caracteres, a compreensão e o tempo de leitura de um texto.

Sob condições normais, é muito difícil entender as operações processadas por um leitor fluente durante a leitura. Considerando processos complexos, os métodos científicos necessitam filtrar a realidade, ou seja, selecionar variáveis a serem manipuladas, observadas e quantificadas isoladamente, e então supor como funcionariam em circunstâncias normais.

O método científico, por selecionar variáveis para manipulação e estudo, não reproduz e não pode reproduzir a complexidade da realidade. (...) O sucesso da teoria depende em grande parte da sensibilidade do pesquisador expressa na seleção inicial de variáveis. (Kolers, 1969: 146, tradução nossa)

Alguns dos critérios utilizados para avaliação do desempenho de leitura são: velocidade de percepção, reconhecimento de caracteres, compreensão do conteúdo, quantidade de erros cometidos, movimentos oculares e frequência de piscadas.

Mas além dos aspectos relacionados diretamente ao reconhecimento de letras e palavras, alguns pesquisadores também consideram a opinião e preferência dos participantes em relação a tipografias e composições tipográficas. Estas avaliações tendem a se colocar como um fator secundário ou um teste prévio com a finalidade de gerar subsídios que auxiliem na seleção dos parâmetros a serem testados em um experimento principal, mas também podem constituir-se como o objetivo principal de uma pesquisa. 
As opiniões dos participantes são levantadas por meio de entrevistas e questionários. Segundo Zachrisson (1965: 69), é importante não apenas construir um sistema de gradação compreensível para o participante e apropriado para o problema, como também deixar claro qual aspecto está sendo avaliado, formulando questões que possam ser entendidas pelos participantes e que conduzam a respostas relevantes para a pesquisa.

Tinker e Paterson (1940: 18) sugerem uma relação entre a opinião de leitores a respeito da legibilidade de tipografias e os resultados de testes de desempenho de leitura. Em um de seus estudos, 210 participantes organizaram dez desenhos tipográficos numa escala de um (menos legível) a dez (mais legível). Legibilidade foi indicada pelos pesquisadores como facilidade e velocidade de leitura. Os resultados deste estudo guardam relação com os resultados dos testes de desempenho de leitura que consideraram as mesmas tipografias.

Em um estudo posterior, de 1942, os autores questionam porque o gosto de um leitor por um desenho de letra parece ser influenciado pelo que ele julga ser mais legível. Ou seja, se um leitor tem maior admiração estética por um desenho de letra que julgue ser mais legível, ou se uma composição mais legível parece mais agradável para o leitor.

Embora seus resultados não indiquem a relação de causalidade entre esses fatores, ainda segundo os pesquisadores, um projeto "deve ser guiado tanto pelos fatores que consideram a velocidade de leitura com que uma determinada composição tipográfica pode ser lida quanto pelo que os leitores julgam ser legível" (Tinker e Paterson, 1942: 40, tradução nossa).

Os dados do estudo de Hvinsttendahl e Kahl (apud Rehe, 1976: 32) reforçam as indicações de Tinker e Paterson, e sugerem uma relação entre a preferência por determinada tipografia e sua maior legibilidade. Os participantes do estudo foram capazes de ler mais rapidamente um texto composto com uma tipografia com serifa, e a mesma tipografia foi apontada como preferida pelos participantes da pesquisa.

Considerando o universo de crianças leitoras iniciais ${ }^{1}$, foram identificadas várias pesquisas de legibilidade que incluíram testes de opinião e preferência (ver Quadro 1). Em muitos casos os resultados deste tipo de investigação serviram para definir os parâmetros do experimento principal.

Os resultados dos testes de opinião e preferência são, em alguns casos, quantificados. Em outros casos, os levantamentos têm caráter exploratório, e a análise dos resultados é feita de modo subjetivo, considerando particularidades de cada participante, como eventuais comentários acerca do tema em questão.

Tendo em vista pesquisas de opinião e preferência que consideraram a leitura realizada por crianças nos anos escolares iniciais, neste trabalho buscou-se identificar aspectos que se demonstram pertinentes para este tipo de investigação. São apresentados tanto dados relativos aos depoimentos das próprias crianças, quanto dos professores alfabetizadores. O objetivo é o de levantar subsídios para possíveis investigações futuras a respeito desse tema.

\footnotetext{
${ }^{1}$ Alunos que cursam o ano que antecede a série escolar de apresentação formal da leitura e da escrita, esta série ou os dois anos seguintes.
} 
Quadro 1: Síntese dos testes de opinião e preferência considerando crianças leitoras iniciantes

\begin{tabular}{|c|c|c|c|c|c|c|c|}
\hline & 1965 & 1980 & 1984 & 1993 & 2003 & 2004 & 2005 \\
\hline $\begin{array}{l}\text { origem da } \\
\text { pesquisa / } \\
\text { instituição }\end{array}$ & $\begin{array}{l}\text { Estocolmo, Suécia } \\
\text { / Instituto Gráfico } \\
\text { de Estocolmo e } \\
\text { Escola de Educa- } \\
\text { ção de Estocolmo }\end{array}$ & $\begin{array}{l}\text { Londres, Inglaterra } \\
\text { Central School of } \\
\text { Art and Design }\end{array}$ & $\begin{array}{l}\text { Reading, Ingla- } \\
\text { terra } \\
\text { School of Educa- } \\
\text { tion da University } \\
\text { of Reading }\end{array}$ & $\begin{array}{l}\text { Inglaterra } \\
\text { Pesquisa indepen- } \\
\text { dente }\end{array}$ & $\begin{array}{l}\text { Rio de Janeiro, } \\
\text { Brasil } \\
\text { Escola Superior de } \\
\text { Desenho Industrial } \\
\text { da Universidade } \\
\text { do Estado do Rio } \\
\text { de Janeiro }\end{array}$ & $\begin{array}{l}\text { Recife, Brasil } \\
\text { Universidade } \\
\text { Federal de Per- } \\
\text { nambuco }\end{array}$ & $\begin{array}{l}\text { Reading, Inglater- } \\
\text { ra / Department } \\
\text { of Typography } \\
\text { and Graphic } \\
\text { Communication, } \\
\text { da University of } \\
\text { Reading }\end{array}$ \\
\hline $\begin{array}{l}\text { objetivo geral } \\
\text { do teste de } \\
\text { opinião e } \\
\text { preferência }\end{array}$ & $\begin{array}{l}\text { Investigar a } \\
\text { opinião das } \\
\text { crianças quanto a } \\
\text { alguns parâmetros } \\
\text { tipográficos }\end{array}$ & $\begin{array}{l}\text { Gerar subsídeos } \\
\text { para teste de lei- } \\
\text { tura com crianças }\end{array}$ & $\begin{array}{l}\text { Investigar a } \\
\text { opinião de } \\
\text { professores sobre } \\
\text { livros de literatura } \\
\text { infantil }\end{array}$ & $\begin{array}{l}\text { Investigar a } \\
\text { opinião das } \\
\text { crianças quanto a } \\
\text { alguns parâmetros } \\
\text { tipográficos }\end{array}$ & $\begin{array}{l}\text { Levantar } \\
\text { subsídeos para } \\
\text { desenvolvimento } \\
\text { de tipografia para } \\
\text { crianças }\end{array}$ & $\begin{array}{l}\text { Avaliar tipografia } \\
\text { desenvolvida para } \\
\text { crianças }\end{array}$ & $\begin{array}{l}\text { Investigar a } \\
\text { opinião das } \\
\text { crianças quanto a } \\
\text { alguns parâmetros } \\
\text { tipográficos }\end{array}$ \\
\hline $\begin{array}{l}0 \text { que foi } \\
\text { pedido aos } \\
\text { participantes }\end{array}$ & $\begin{array}{l}\text { Grupos tipográ- } \\
\text { ficos com e sem } \\
\text { serifa e tamanhos } \\
\text { de corpo de letra } \\
\text { diferentes }\end{array}$ & $\begin{array}{l}\text { Avaliar desenhos } \\
\text { tipográficos como } \\
\text { adequado ou } \\
\text { inadequado para } \\
\text { leitura de crianças }\end{array}$ & $\begin{array}{l}\text { Ordenar } 5 \\
\text { caracterícticas } \\
\text { de livros de } \\
\text { literatura infantil, } \\
\text { a partir de uma } \\
\text { lista contendo 14, } \\
\text { que julgassem } \\
\text { importantes }\end{array}$ & $\begin{array}{l}\text { Apontar desenhos } \\
\text { e composições } \\
\text { preferidas }\end{array}$ & $\begin{array}{l}\text { Indicar, a partir } \\
\text { de uma lista, os } \\
\text { desenhos tipográfi- } \\
\text { cos que julgassem } \\
\text { mais adequados } \\
\text { para serem utiliza- } \\
\text { dos em livro }\end{array}$ & $\begin{array}{l}\text { Indicar se perce- } \\
\text { biam diferenças } \\
\text { entre composições, } \\
\text { e selecionar um } \\
\text { desenho preferido, } \\
\text { no caso das } \\
\text { professoras, tendo } \\
\text { em vista crianças } \\
\text { em processo de } \\
\text { alfabetização }\end{array}$ & $\begin{array}{l}\text { Indicar se perce- } \\
\text { biam diferenças } \\
\text { entre composi- } \\
\text { ções e selecionar } \\
\text { desenhos que } \\
\text { julgassem ser mais } \\
\text { fáceis de serem } \\
\text { lidos }\end{array}$ \\
\hline
\end{tabular}

\section{Pesquisas com professores}

Coghill (1980) utilizou um questionário com a finalidade de auxiliar na seleção dos desenhos a serem utilizados no teste de leitura principal de sua pesquisa, realizada com crianças em processo de alfabetização. No questionário, respondido por 50 professores, foi primeiramente apresentada uma frase composta com Gill Sans precedida de uma pergunta sobre a adequação deste desenho ao público infantil. Em seguida, outros quatro desenhos tipográficos eram apresentados e era pedido ao participante para designá-los como adequado ou não adequado.

Todos os participantes, com exceção de um, definiram a tipografia sem serifa como sendo adequada, 35 deles apontaram a tipografia sem serifa como única opção adequada, e 26 indicaram em seu comentário que sua escolha se devia ao fato desta tipografia guardar mais semelhanças com a escrita inicial feita por crianças. A maioria dos comentários fazia menção à simplicidade formal do desenho sem serifa, e sua maior relação com as capacidades das crianças, 
mesmo sem possuir qualquer outro acabamento que remetesse à escrita manual, como os caracteres para crianças ${ }^{2}$.

Diferentemente das demais pesquisas apresentadas neste tópico, a de Raban (1984) não buscou avaliar a opinião ou preferência de professores acerca de desenhos ou composições tipográficas, mas de características gerais de livros de literatura infantil.

Por meio de um questionário, 270 professores atribuíram grau de importância aos elementos que consideravam relevantes na escolha de um livro para crianças. Foi pedido aos participantes que ordenassem cinco características, a partir de uma lista contendo 14. Além disso, eles deveriam indicar mudanças na ordenação, caso julgassem necessárias, considerando crianças de idades diferentes, entre 5 e 7 anos.

O conteúdo da história foi apontado como característica mais importante para crianças com 6 ou 7 anos de idade. Entretanto, para crianças com 5 anos de idade, tanto a qualidade das ilustrações quanto o uso de um vocabulário controlado foram considerados mais importantes.

A quarta característica considerada mais importante para crianças de 5 anos de idade foi o tamanho das letras. Cinquenta e quatro por cento dos participantes julgaram que as questões discutidas eram irrelevantes para as crianças a partir dos 7 anos de idade, $36 \%$ acharam que a tipografia impressa deve ser compatível com a escrita, $14 \%$ defenderam o uso dos caracteres para crianças, $11 \%$ deram maior importância ao tamanho do corpo, 10\% enfatizaram o uso de formas simples para as letras, $5 \%$ julgaram que os itens em questão eram irrelevantes em qualquer etapa do aprendizado, e 2\% mencionaram o espacejamento (Sassoon, 1993: 151).

Foi também pedido aos participantes que indicassem, entre tipografias com e sem serifa, e entre caracteres regulares e caracteres para crianças, quais julgavam mais adequados ao público infantil.

Dois terços dos professores julgaram a tipografia sem serifa mais adequada, e $39 \%$ deles mencionaram que deve haver uma correspondência entre letra impressa e a escrita. A preferência pelos caracteres alterados foi marcante, embora menos evidente considerando crianças de 7 anos de idade.

Durante o desenvolvimento do projeto Tipografia para Crianças (Rumjanek, 2003), que resultou na construção de uma tipografia específica para esse público, buscou-se ouvir a opinião de professoras alfabetizadoras sobre qual julgavam ser uma tipografia adequada para esses leitores.

Foi apresentada uma lista contendo o mesmo texto composto com tipografias diferentes comumente presentes em livros de literatura infantil encontrados em bibliotecas de escolas. A tipografia Futura, única do grupo que possuía "a" e "g" cursivos, foi apontada pela maioria das professoras como sendo mais apropriada por possuir um desenho simples e alguns caracteres mais próximos da escrita manual realizada na escola. Entretanto, muitas estavam cientes das ambiguidades geradas por esse desenho geométrico.

Gusmão (2004: 75) também realizou testes de preferência com desenhos tipográficos. Seus testes compararam quatro desenhos: AlphaBetica ${ }^{3}$, Comic Sans, Avant Garde e Times New Roman (figura 1).

Figura 1: Desenhos tipográficos utilizados no estudo de Gusmão (2004: 74). (usado com a permissão de Gusmão)

\section{abcdefghijk abcdefghijk abcdefghijk abcdefghijk}

\footnotetext{
${ }^{2}$ Em inglês, infant characters, refere-se a caracteres alternativos, que têm formas mais próximas às da escrita manual, como o "a" e o " $g$ " cursivos.

${ }^{3}$ A tipografia AlphaBetica foi desenvolvida por Gusmão especificamente para leitores iniciais.
} 
O teste foi realizado com 37 crianças, com idades entre 5 e 7 anos, e dez professoras de uma escola municipal em Recife, Pernambuco.

Foi perguntado às professoras se percebiam alguma diferença entre os desenhos e, àquelas que percebiam, era pedido que indicassem qual daqueles consideravam mais apropriado para o público em questão.

Todas as professoras participantes perceberam diferenças entre as pranchas. A maioria selecionou a tipografia Avant Garde como mais adequada ao público infantil, alegando que as crianças estariam mais familiarizadas com suas formas de geometria simples.

\section{Pesquisas com crianças}

Zachrisson $(1965: 131,139)$ usou testes de opinião para investigar a percepção de crianças de $1^{\text {a }}$ e $4^{a}$ série em relação a desenhos tipográficos (figura 2) e tamanhos de corpos de letra diferentes. Os testes foram realizados com 72 meninos da $1^{\text {a }}$ série, oriundos de duas escolas distintas - em uma o material de leitura era composto com tipografia sem serifa, e na outra, com serifa - e 48 crianças (24 meninos e 24 meninas) da $4^{\text {a }}$ série.

Foi pedido aos participantes que ordenassem as tipografias segundo a que achavam mais fácil de ser lida, convidativa, agradável, entre outras características. Apenas a hierarquia apontada por cada participante foi registrada. Entretanto, não foi obtida uma diferença significativa nos resultados.

Com o mesmo universo amostral, Zachrisson realizou um teste de opinião onde comparou diferentes tamanhos de corpo de letra. Aos alunos da $1^{\text {a }}$ série, o material de texto para o teste foi apresentado nos corpos de letra de 10, 14 e 16 pontos, e aos alunos da $4^{a}$ série, nos corpos de letra de 8,10 e 12 pontos. Segundo o pesquisador, houve uma diferença significativa. No grupo de alunos de $1^{\text {a }}$ série foi identificada uma grande popularidade do corpo de letra de 16 pontos. A diferença não foi tão marcante no grupo de alunos da $4^{a}$ série, particularmente entre os corpos de 10 e de 12 pontos. Entretanto, houve uma diferença grande na comparação destes com o corpo menor, de 8 pontos (quadros 2 e 3 ).

Figura 2: De cima para baixo, da esquerda para a direita: Bembo, Nordisk antikva, Mager Konsul e Gill Sans. (Zachrisson, 1965: 101)

Hur mår ni, barn? sa mor. Vi mår bra, sa Siv. Se här, mor, så fin vår båt är! Vi ror så bra nu. Farmor och

Hur mår Ni barn? sa mor. Vi mår bra, sa Siv. Se här, mor, så fin vår båt är! Vi ror sả bra nu. Farmor och farfar hälsar från
Hur mår ni, barn? sa mor. Vi mår bra, sa Siv. Se här, mor, så fin vår båt är! Vi ror så bra nu. Farmor och farfar hälsar

Hur mår ni barn? sa mor. Vi mår bra, sa Siv. Se här, mor, så fin vår båt är! Vi ror så bra nu. Farmor och farfar häl-

Quadro 2: Opinião de leitores (média da hierarquização) referente aos desenhos tipográficos. (Zachrisson, 1965: 132)

\begin{tabular}{lllll}
\hline & COM SERIFA 1 (BEMBO) & COM SERIFA 2 (NORDISK) & SEM SERIFA 1 (MAGER) & SEM SERIFA 2 (GILL) \\
\hline $\begin{array}{l}1^{\text {a }} \text { SÉRIE } \\
\text { material escolar sem serifa }\end{array}$ & 2,4 & & & \\
\hline material escolar com serifa & 2,6 & 2,6 & 2,7 & 2,3 \\
\hline 4a SÉRIE & 2,6 & 2,6 & 2,4 \\
idades 8-11 & 2,3 & 2,3 & 2,5 & 2,9 \\
\hline
\end{tabular}


Quadro 3: Opinião de leitores referente aos tamanhos de corpo de letra. (Zachrisson, 1965: 140)

\begin{tabular}{ll}
\hline tamanHO (PONTOS) & PRIMEIRA OPÇÃO (NÚMERO DE VEZES) \\
\hline $1^{\text {a } \text { SÉRIE }}$ & \\
10 & 5 \\
\hline 14 & 25 \\
\hline 16 & 42 \\
\hline & 72 \\
\hline
\end{tabular}

\begin{tabular}{ll}
\hline TAMANHO (PONTOS) & PRIMEIRA OPÇăO (NÜMERO DE VEZES) \\
\hline $4^{2}$ SÉRIE & \\
8 & 11 \\
\hline 10 & 33 \\
\hline 12 & 28 \\
\hline & 72 \\
\hline
\end{tabular}

Sassoon (1993) buscou avaliar a percepção de crianças em relação a desenhos tipográficos e espacejamentos diferentes. Sassoon relata que esteve envolvida com desenhos de letras por toda sua vida, mas se envolveu com questões ligadas a projetos tipográficos apenas mais tarde, próximo à data de seu estudo (Sassoon, 1993: 152).

A pesquisadora conta que constatou a importância de voltar seu estudo para tais questões quando foi abordada por uma professora de alunos com dificuldades de aprendizado que disse não entender porque eles eram capazes de ler uma página de texto e não conseguiam ler a página seguinte, já que as duas possuíam mesmo nível de dificuldade. Sassoon notou rapidamente que o texto causando dificuldades estava alinhado de modo justificado, fato que a professora não tinha sido capaz de perceber.

A principal questão levantada por Sassoon é a de que as decisões sobre os parâmetros próprios para crianças são feitas por adultos, sejam eles educadores, sem um conhecimento maior sobre desenhos de letras, ou designers, que, segundo a autora, tendem a privilegiar as questões estéticas em detrimento dos interesses das crianças.

Seu estudo foi desenvolvido de modo independente, e não foi definido um método específico, dependendo da disponibilidade das professoras participantes. O problema foi abordado de maneira distinta por cada participante, e apenas uma professora produziu um estudo significativo. As professoras participantes não tinham um conhecimento tipográfico particular, o que, na opinião da pesquisadora, pareceu adequado para que seus próprios pontos de vista não interferissem em seus julgamentos.

Os testes da pesquisa foram realizados utilizando cinco variações de espacejamento e 4 tipografias diferentes: uma tipografia sem serifa inclinada, a Times, por ser uma tipografia amplamente difundida, a Times itálico, por ser utilizada para crianças que apresentam problemas de aprendizado, e a Helvetica com caracteres para crianças (figura 3).

Figura 3: Exemplos de desenhos tipográficos utilizados no estudo de Sassoon (1993).

He was right out of the water and away from

the waves and he lay still. He rolled on to his

He was right out of the water and away

from the waves and he lay still. He rolled on

He was right out of the water and away

from the waves and he lay still. He rolled on

He was right out of the water and away from

the waves and he lay still. He rolled on to his

A professora que realizou um estudo completo utilizou 100 crianças, metade delas eram alunos com necessidades especiais de 8 a 13 anos de idade, e a outra metade, crianças de 8 anos de idade de turmas regulares. Para o primeiro grupo, eram mostrados todos os desenhos tipográficos e, em seguida, perguntado qual era o preferido. As variações de espacejamento, dentre as quais a 
criança também deveria selecionar uma preferida, eram então apresentadas todas na tipografia previamente apontada pela criança. Para o grupo de alunos de turmas regulares, a professora apresentava todas as alternativas, variações de desenhos tipográficos e espacejamentos, e pedia para que a criança selecionasse sua opção preferida e aquela que julgava mais fácil para se ler.

As escolhas variaram dependendo da habilidade de leitura dos participantes. Segundo a professora, as crianças com mais dificuldades preferiram espacejamento largo e tipografia neutra (sem serifa inclinada). As crianças com melhor desempenho de leitura gostavam de ler a tipografia com desenho mais próximo da cursiva (Times itálico) e com menos espacejamento.

Foram identificadas algumas opiniões comuns, como o desejo por uma leve inclinação e uma grande preferência pelos desenhos sem serifa. Para Sassoon, os resultados da pesquisa indicam que as crianças são capazes de fazer as diferenciações necessárias à avaliação dos desenhos distintos.

Às 37 crianças que participaram do estudo de Gusmão (2004: 74), foram feitas duas perguntas: se elas eram capazes de perceber diferenças entre os quatro desenhos e, nos casos em que isto se dava, qual dos desenhos a criança preferia.

Do total de crianças, apenas 12 perceberam as diferenças entre as pranchas. Entre essas, seis optaram pela Comic Sans, quatro pela Alphabetica, duas pela Avant Garde e uma pela Times New Roman.

As crianças não foram capazes de justificar suas preferências. O autor questiona se a grande preferência pela Comic Sans pode estar relacionada a sua linguagem próxima a de caligrafias e tipografias utilizadas em histórias em quadrinhos.

O teste de desempenho de leitura da pesquisa coordenada por Walker (2005), que avaliou 11 tipografias (figura 4) e 12 variações de espacejamentos, não obteve resultados significativos. Entretanto, segundo a opinião da autora, informações importantes foram coletadas nas entrevistas de opinião e preferência realizadas com as mesmas 24 crianças participantes do teste. Foi perguntado aos participantes: se podiam identificar diferenças na aparência da escrita, se havia algum estilo que preferiam e qual dos estilos achavam mais fácil de ser lido.

Figura 4: Tipografias utilizadas no estudo coordenado por Walker (2005).

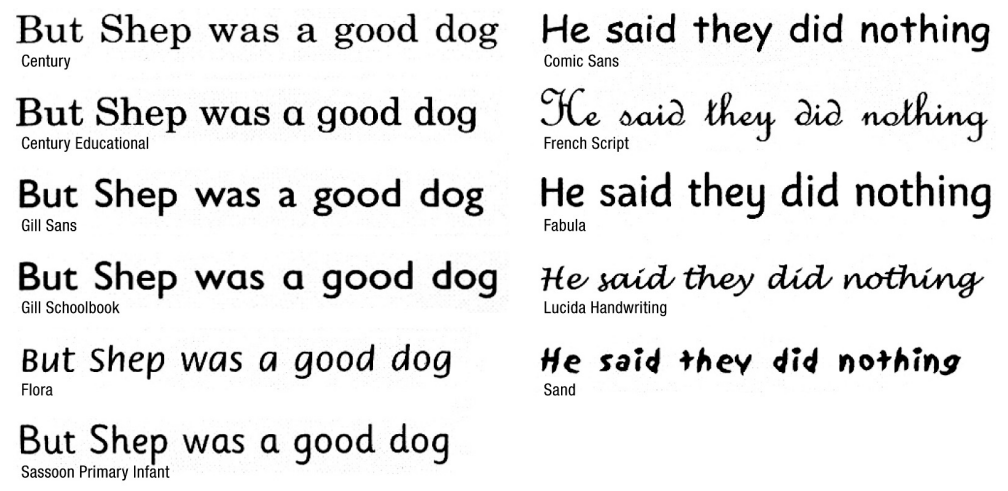

No primeiro teste, onde foram utilizadas as tipografias Gill Sans, Century, Gill Schoolbook e Century Educational, dentre as 24 crianças, 15 foram capazes de detectar diferenças entre os estilos apresentados. Oito crianças preferiram a Gill Sans, três, a Gill Schoolbook, duas, a Century, três, a Century Educational, e oito crianças não demonstraram preferência alguma.

Com relação ao grupo de tipografias sem serifa, foram feitas afirmações pelas crianças tais como: "as letras aparecem mais e são bem maiores para se ler" ou "parece fácil para eu ler". Com relação ao grupo com serifa, foi dito por uma das crianças: "é bastante fácil de se ler, e tem uma aparência diferente".

Considerando os caracteres para crianças e os caracteres regulares, a maior parte das crianças estava atenta quanto à diferença de formas das letras e muitas fizeram a observação de que o desenho alternativo (com caracteres para crianças) é para quando se escreve e o desenho 
original, para quando se lê. Algumas crianças julgaram o " $g$ " romano como sendo mais difícil para se ler, mas leram ambos com a mesma fluência nos testes de desempenho.

No segundo grupo de testes, que comparou as 4 tipografias anteriores com a Flora e a Sassoon Primary Infant, as crianças acharam o desenho da Flora mais "arredondado", "sofisticado" e "adulto". Ainda segundo suas opiniões, a Century foi descrita como "normal" e a Sassoon como "se alguém a tivesse escrito, fluindo".

Foi testado ainda um terceiro grupo de tipografias. Algumas das expressões utilizadas pelas crianças para avaliar as tipografias foram:

Comic sans: "escrita de bebê" e "como a escrita de quadrinhos"

French script: "estrangeira", "de menininha", "como nos dias de antigamente" e "escrita de cartão de aniversário"

Fabula: "escrita de verdade" e "como um livro comum"

Lucida handwriting: "à moda antiga" e "especial"

Sand: "fácil porque não tem letras ligadas"

Algumas descrições utilizadas pelas crianças indicam que algumas tipografias podem afetar a motivação, como "mais inteligente" e "mais rápida". Algumas opiniões dizem respeito à adequação, pois determinadas tipografias foram consideradas como menos apropriadas para uso em livros de literatura infantil e, ao mesmo tempo, como sendo atraentes. Segundo uma criança, a respeito da French Script, "eu não consigo lê-la muito bem, mas gosto de sua aparência".

Nos testes também foram apresentadas quatro variações de espacejamentos entre letras, palavras e de entrelinhas. Um número maior de crianças conseguiu perceber os diferentes espacejamentos entre letras, em relação ao grupo capaz de identificar os diferentes espacejamentos entre palavras. Tanto para o espacejamento entre letras quanto para $o$ espacejamentos entre palavras, as alternativas preferidas pelas crianças variaram entre as normais e as mais afastadas. Segundo a percepção de algumas crianças, o espacejamento entre letras mais apertado foi responsável por tornar o texto mais difícil de se ler, e fez com que as letras parecessem mais escuras, grossas e pequenas.

Considerando as diferentes entrelinhas, as alternativas que variavam entre normais e mais espaçadas também foram apontadas como preferidas pelas crianças. Algumas das qualidades destas alternativas apontadas por elas foram: clareza, facilidade de leitura e proximidade com a realidade.

Assim como no estudo de Sassoon, as respostas das crianças que participaram do estudo de Walker demonstram que elas são capazes de perceber diferenças nos desenhos e possuem opiniões a respeito dos mesmos. Além disso, é possível observar que desde cedo os desenhos tipográficos diferentes são associados como sendo próprios a universos específicos. Para Walker, os comentários das crianças sobre as variações tipográficas sugerem que as questões abordadas têm um efeito considerável sobre suas motivações para escolher um livro e, de fato, lê-lo.

\section{Considerações sobre pesquisas de opinião e preferência}

Tendo em vista os estudos apresentados neste trabalho, é possível destacar duas questões de fundo: [a] as diferenças de experiências e pontos de vista entre crianças e professoras alfabetizadoras; [b] a falta de um conhecimento mais amplo a respeito de aspectos tipográficos por parte tanto de professores quanto de alunos. As diferenças entre desenhos de letras estão, fundamentalmente, em detalhes, com poucas exceções, o desenho básico das letras é bastante próximo. Por isso, uma avaliação eficaz exige uma grande atenção a pequenos detalhes, como acabamentos ou variações na espessura de traços.

Em relação à primeira questão, pode-se destacar os julgamentos de professores baseados no ensino da escrita. Para alguns deles, as letras maiúsculas, por exemplo, representam uma escrita que exige menos da coordenação motora de seus alunos, parecendo, deste modo, apropriada para aqueles que estão no processo inicial da alfabetização. Do mesmo modo, há um entendimento de que as formas de um desenho sem serifa, por serem mais simples, facilitam a leitura realizada por crianças. Esses desenhos também são considerados como sendo mais próximos da escrita da própria criança, por não possuir os acabamentos ou detalhes específicos 
dos desenhos com serifa ou suas formas mais rebuscadas. Este fato tem relação com outra questão discutida com frequência sobre a relação entre o desenho de letra impresso e da escrita manual. Muitos professores acreditam que a maior proximidade entre os dois desenhos facilita tanto o aprendizado da escrita, quanto o da leitura, o que parece apontar uma dificuldade de percepção de que a leitura e a escrita são processos distintos. Isto, por sua vez, pode levar à recomendação de uso, por parte de professores, dos mesmos desenhos de letras tanto para a escrita quanto para materiais impressos.

Um dos motivos que leva pesquisadores a buscarem ouvir a opinião de professores é a quantidade pequena de estudos realizados especificamente com crianças e, ainda, os resultados pouco conclusivos obtidos nos mesmos, especialmente naqueles que consideraram diferentes desenhos tipográficos. O que acaba por impossibilitar a utilização dos resultados de pesquisas prévias para definir parâmetros tipográficos, dentre outros critérios, para um novo experimento.

Quanto à segunda questão, pode-se observar que em qualquer experimento é necessário um grande cuidado na seleção das variáveis a serem medidas. No tipo de pesquisa em questão, essa seleção não deve ser feita de modo diferente. Além disso, deve haver uma busca pelo entendimento do olhar do leigo, e pelos significados que um determinado desenho tipográfico pode ter para tais participantes.

Em países como a Inglaterra, onde há uma cultura tipográfica mais consolidada, questões tipográficas técnicas não ficam necessariamente restritas ao meio profissional do design. Conforme pode ser observado nos estudos descritos e segundo Walker, educadores e editores de livros infantis possuem uma forte opinião sobre o desenho tipográfico apropriado para crianças leitoras. O que não significa, entretanto, que por isso suas recomendações são de fato as mais adequadas. No Brasil esta cultura tipográfica fora do meio profissional é praticamente inexistente como pode ser observado a partir da pesquisa Tipografia para Crianças (Rumjanek, 2003), as professoras alfabetizadoras demonstraram ausência de uma relação prévia e sistemática com os desenhos de letras.

Diferentemente do designer ou tipógrafo, o julgamento de educadores em relação às tipografias não é influenciado por questões como suas classificações usuais, contraste, eixo de estresse, acabamentos, entre outros, mas por outras questões, como suas relações com a escrita, conforme descrito anteriormente. Deste modo, torna-se importante buscar, sobretudo, uma definição de variáveis adequadas às experiências de percepção da tipografia pelos participantes. Além disso, um dos problemas com o qual as pesquisas de opiniões e preferências precisam lidar é a subjetividade dos termos utilizados para classificar o que estiver sendo avaliado pelos participantes. Um mesmo adjetivo, por exemplo, pode ter significados diferentes para pessoas distintas, embora grande parte de seu sentido esteja contido nele mesmo, uma parte depende da experiência individual.

Desmet (2002), em sua tese Designing Emotions, procurou minimizar ao máximo essas diferenças de interpretação. O pesquisador buscou criar um sistema para avaliar produtos por meio das emoções que estes evocam. O sistema final consiste de um personagem animado que representa emoções diferentes, e pode ser utilizado para avaliar qualquer aspecto que envolva emoções, de produtos e situações, a obras de arte e tipografias, por exemplo. Para selecionar as palavras que representam emoções para seu estudo, foi traçado um percurso cuidadoso que visava a eliminar palavras que representassem emoções ambíguas ou duplicadas. Foi feita uma série de testes com participantes para avaliar o entendimento do significado das palavras. Os testes realizados eram capazes de medir, por exemplo, se a palavra felicidade possui aproximadamente o mesmo significado para pessoas distintas, ou se as emoções representadas pelas palavras tristeza e melancolia podem ser diferenciadas com clareza uma da outra.

A vantagem do sistema gerado nesse estudo é sua menor probabilidade de utilizar termos que suscitem diferentes interpretações, podendo assim quantificar, com maior precisão, opiniões de participantes sobre aspectos diversos. O mesmo tipo de aproximação aplicado aos testes que envolvem opiniões e preferências acerca de tipografias poderia gerar resultados mais confiáveis. Além disso, o sistema permite que o pesquisador selecione as qualidades que utilizará em suas classificações, não dependendo apenas do repertório dos participantes de sua pesquisa.

O problema deste tipo de abordagem está em sua própria natureza, a tentativa de criar um repertório delimitado de critérios de avaliação, que acaba desconsiderando qualquer posicionamento mais particular de determinado participante.

De um modo geral, as pesquisas de opinião e preferência relacionadas a tipografias próprias 
para serem utilizadas em material de literatura infantil não utilizaram uma metodologia que tentasse prever e minimizar questões que são afetadas por uma diferença de interpretação entre indivíduos.

Ovink (1938 apud Zachrisson, 1965: 69), em sua pesquisa, também buscou minimizar as dificuldades implícitas na investigação de aspectos subjetivos. Seu estudo é um exemplo ainda mais extremo de delimitações desta natureza. Ele realizou uma pesquisa de opinião a respeito de desenhos tipográficos com 139 participantes. A única qualidade avaliada em seu teste foi a clareza dos desenhos. Foi pedido aos participantes que atribuíssem um valor a partir de uma escala com três gradações (entre claro e não claro) a cada um dos desenhos apresentados. Uma hierarquização de muitos itens similares (outras qualidades) acarretaria dificuldades de execução mesmo para especialistas. Se, por um lado, o pesquisador precisou limitar as possibilidades de seu estudo, por outro, alcançou resultados, provavelmente, mais confiáveis, por meio de um teste que gerou menos dificuldades e confusões para seus participantes.

Uma outra solução utilizada para este tipo de questão, pode ser encontrada no livro de Spiekermann e Ginger (1993: 40) destinado a pessoas que estão iniciando o contato com tipografia. O livro busca utilizar estereótipos para tornar a aproximação de questões relacionadas a desenhos de letras mais acessível. No exemplo, uma tipografia deve ser associada a um estilo de calçado, essa associação é feita de modo intuitivo, pois não existe uma regra pré-estabelecida sobre esse aspecto. Esta aproximação exige um entendimento maior sobre as associações que são feitas nestas relações, e sobre como ocorrem de maneira coletiva.

Um último aspecto referente ao desenvolvimento de pesquisas de opinião e preferência tendo em vista o universo de crianças leitoras iniciais diz respeito à possível consolidação de novos critérios que sejam adequados a uma nova ordem de objetivos. Nas pesquisas de desempenho de leitura, por exemplo, privilegia-se as leituras realizadas em menor tempo e com menor número de erros cometidos, sem prejuízo de compreensão do conteúdo, quando este critério também é avaliado. Pesquisas de opinião e preferência parecem apontar para fatores mais subjetivos, como a motivação e o prazer da leitura, que podem não estar associados a uma maior velocidade ou qualquer outro aspecto que normalmente define o melhor desempenho. A observação de aspectos de ambas as naturezas pode propiciar uma compreensão mais ampla sobre o tema.

\section{Agradecimento}

Á Rosemary Sassoon por ter gentilmente cedido o relatório da pesquisa de Bridie Raban.

\section{Referências}

COGHILL, V. 1980. Can children read familiar words set in unfamiliar type? Information Design Journal, v. 1, n. 4: 254-260.

DESMET, P. 2002. Designing Emotions. Tese de doutorado apresentada à Delft University of Technology. Holanda.

GUSMÃO, G. 2004. AlphaBetica: família tipográfica para leitores iniciantes. Monografia apresentada ao Curso de Design da Universidade Federal de Pernambuco. Recife.

KOLERS, P. A. 1969. Clues to a letter's recognition: implications for the design of characters. The Journal of Typographic Research, v. 3, n. 2: 145-168.

RABAN, B. 1984. Survey of teachers' opinions: children's books and handwriting styles. In: Dennis, D. (Ed.) Reading: meeting children's special needs: 123-129. Londres: Heinemann.

REHE, R. F. 1974. Typography: how to make it most legible. Connecticut: West Port.

SASSOON, R. 1993. Through the eyes of a child: perception and type design. In: Sassoon, R. (Ed.). Computers and typography: 150-177. Oxford: Intellect Books.

RUMJANEK, L. 2003. Tipografia para crianças. Monografia apresentada ao curso de graduação de desenho industrial da ESDI/UERJ. Rio de Janeiro.

SPIEKERMANN, E. \& GINGER, E. M. 1993. Stop stealing sheep and find out how type works. Califórnia: Adobe Press. 
TINKER, M. A. \& PATERSON, D. G. 1940. How to make type readable. Nova lorque: Harper \& Brothers Publishers.

1942. Reader preferences and typography. Journal of Applied Psychology, v. 26: 38-40.

WALKER, S. 2005. The songs the letters sing: typography and children's reading. National Centre for Language and Literacy: Reading.

ZACHRISSON, B. 1965. Studies in the legibility of printed text. Stockholm: Almqvist \& Wiksell.

\section{Sobre os autores}

Letícia Rumianek, Mestre, graduada em Desenho Industrial pela ESDI/UERJ (2003) com habilitação em Projeto de Produto e Comunicação Visual. Mestre também pela ESDI/UERJ, com a pesquisa Tipografia para crianças: estudos de legibilidade (2009).

<lerumjanek@gmail.com>

Washington Dias Lessa, Doutor, graduado pela ESDI/UERJ, é professor desta instituição desde 1977, integrando, atualmente, o seu programa de pós-graduação. É mestre em Educação pelo IESAE/FGV, e doutor em Comunicação e Semiótica pela PUC/SP.

$<$ wdlessa@esdi.uerj.br> 